\title{
1. Globalization and mobility
}

This book aims at the joint and comparative examination of the five major, and rather voluntary, global movements of commodities and people, capital, information and technology, and thus excluding forced migrations of refugees. The discussions of these specific movements will follow several introductory presentations of globalization and spatial mobility in general, and of mobility in globalization in particular, in this chapter. Each of the five major global mobilities includes some sub-classes. For the mobility of commodities, the elaborations will include exports and imports, whereas for people they will refer to tourists and workers. For capital, the examination will focus on a variety of global transactions, and mainly on interbank transmissions, payment cards, foreign investments and venture capital, as well as on stock market portfolio investments and foreign exchange. For information, the discussion will relate mainly to the Internet, as well as to telephony and television (TV) transmissions. Finally, for technology the exposition will target mainly high-tech technology locations and transfers.

Side by side with the exploration of these rather varied global mobilities, the book will discuss the means and media used for their operations, and these media include ports and ships for exports and imports, airports and airplanes for tourists and workers, as well as for exports and imports. In addition, international banking electronic media, such as the Society for Worldwide Interbank Financial Telecommunication, will be presented for capital transfers, and the Internet, telephony and TV will be exposed for information and technology transmissions.

Following this introductory chapter, focusing on globalization, spatial mobility and global mobilities in general, the book will devote two chapters to each of the five major global mobilities: commodities, people, capital, information and technology. The first of these two chapters will be devoted to the relevant media for each mobility type, followed by a chapter describing and assessing the specific mobility in light of the media that serve its operations, focusing mainly on the development, structure, trends and patterns for each mobility type. The two concluding chapters of the book will constitute general and comparative explorations of the mobile globe, and they will attempt to highlight the status of global mobility in general, as well as the relationships among the five global mobilities in particular. These two discussions will be 
followed by an assessment of possible future development in the leadership of global mobilities.

The nature of the body of the book (Chapters 2-10) is obviously empirical and partially descriptive, attempting to present a contemporary synopsis of the numerous dimensions of global mobilities. However, the framework for the book is rather conceptual. Thus, the general literature reviews for the book, referring to globalization and spatial mobility in general, as well as to global mobilities in particular, will be the main topics for Chapter 1, and the two last chapters of the book (11 and 12) will focus on comparisons and syntheses for the trends presented in the body of the book.

This introductory chapter will introduce, first, some definitions for globalization, as a process and pattern. Explorations of the historical and colonial roots, as well as the emergence and factors for the patterns and processes of contemporary globalization, will follow. The chapter will then outline the notion of spatial mobility. These two brief introductions to globalization and mobility will be followed by a focus on the relationships between globalization and mobility, arguing that in its essence, globalization consists, as a process and pattern, of a series of global mobilities, jointly constituting the mobile globe. These global mobilities include commodities, people, capital, information and technology. Finally, the chapter will discuss contemporary objections to globalization, leading to some governmental withdrawals from its continued fostering.

\subsection{THE NATURE OF GLOBALIZATION AND ITS DEFINITIONS}

There has accumulated, notably over the last three decades, a wide array of literature on globalization in general, and about its nature in particular. The discussion in this, as well as in the following sections of this chapter, is not aimed at the provision of a comprehensive relevant literature review, but rather to point to some central aspects and perspectives, which may be of relevance for a joint discussion of globalization and mobilities. Thus, it was recently for Kloosterman et al. (2018), for example, to have reviewed the history of the term 'globalization', dating back to 1930 .

The very nature of globalization has been assessed from three angles (Shamir 2005). First, globalization might be conceived as a kind of a system, as a network society (e.g. Held et al. 1990; Castells 1996), consisting of spaces, flow routes and movement vehicles, all of which facilitate global mobilities. Castells (1996, 2000), as we will see later (Section 2.5), suggested the space of places as being currently replaced by the space of flows, thus calling for a networked logic to replace the past territorial one, as the leading principle in global spatial organization. As we will note throughout the book, the con- 
temporarily developed mobility technologies, coupled with the emergence of politically opened national borders, have brought about a world governed more by global flows than by domestic places and spaces.

Second, globalization constitutes no less than the wide variety of the seamless global mobilities themselves, including people, commodities, technologies and cultures (e.g. Lechner and Boli 2000; Appadurai 1996; Anderson et al. 2003; Giddens 1990). Third, and from a radical perspective, globalization has been assessed to amount to transnational capitalism, expressed through the global movements of capital (e.g. Sklair 1997; Gottdiener 1995; Harvey 1989; Soja 1989). Thus, capital has been recognized as having a double role for the emergence of globalization, since it constitutes both a generating force for globalization and global mobilities at large, side by side with its constitution of a rather specific globally moving resource. Currently, information technology (IT) has also received such a double status for the emergence of globalization: globalization systems and the global movements, which it facilitates, are fully dependent on IT for their very functioning and synchronization, side by side with IT being globally transmitted and sold, and thus constituting a rather specific global movement by itself.

The following chapters will attempt to present globalization through the three angles of its simultaneous constitution of a system, movements and capital-generated process. Thus, the chapters focusing on movement facilities and vehicles (Chapters 2, 4, 6, 8) will amount jointly to the portrayal of globalization as a system, whereas the chapters devoted to the movements themselves (Chapters 3, 5. 7, 9-10) will present globalization as movements. Chapter 6 will expose also the roles of capital and the capitalist system for the emergence and operation of globalization in general, side by side with the exposition of capital as a movement by itself.

Definitions for globalization focus on relevant processes and patterns, and they jointly reflect the societal facets of globalization, whether it be a system, a collection of movements or a capitalist venture. They present, therefore, numerous meanings and significances of globalization, for people as well as for countries, both of whom simultaneously activate globalization and are activated by it. Definitions for globalization are even more varied than the three perspectives suggested for the nature of globalization, as the following sample demonstrates (Gopinath 2018):

1. Processes and outcomes: Globalization - the umbrella term for the complex set of transformative processes and outcomes that, dialectically and rationally, interact with places and people (Dicken 2004, 17).

2. Integration: Globalization is the inexorable integration of markets, nation-states and technologies to a degree never witnessed before (Friedman 2000, 9). 
3. Social relations: Globalization is the intensification of worldwide social relations, which link distant localities in such a way that local happenings are shaped by events occurring many miles away and vice-versa (Giddens 1990, 64).

4. Existential environment: Globalization is the environment in which we live. We have one world. Get used to it. Make the most out of it. Debating globalization? It is like asking fish to debate the merits of living in the sea (McNamee 2004, 68).

5. Experience: Globalization, in its most general sense, [as] is the process whereby the world becomes a single place (Robertson 1992, 135).

6. Social processes: Globalization refers to a multidimensional set of social processes that create, multiply, stretch and intensify worldwide social interdependencies and exchanges, while at the same time fostering in people a growing awareness of depending connections between the local and the distant (Steger 2003, 13).

7. Barrier removal: Globalization - the removal of barriers to free trade and the closer integration of national economies (Stiglitz 2002, ix).

8. Human activity: Globalization represents the continuing effort by the peoples of the world to interact and share transnationally in the pursuit of their objectives (Gopinath 2018, 13).

\subsection{HISTORICAL ROOTS FOR GLOBALIZATION AND ITS DEVELOPMENT}

Global mobilities do not constitute a novel trend. Already in ancient times, merchants and governments were involved in exporting and importing, notably of precious products, thus developing historical long-distance roads, such as the Silk Road and Via Maris. Global mobilities have emerged more extensively as of the eighteenth century, with the introduction of steamboats and railways. The development of IT, as well as of transportation technologies for all vehicle modes, coupled with proper political and economic conditions, have brought about, notably as of the 1970s, the emergence of contemporary globalization in general, and of global mobilities in particular.

Gopinath (2018) traced globalization back to the city of Ashur (in contemporary Iraq), dating back to $3000 \mathrm{BC}$, with the city being located at the intersection of international trade routes. Similar ancient nodes have emerged later on in other cities, located in numerous regions, such as along the Red Sea, in India, China and North Africa, as well as in Europe, notably in Greece. Gopinath (2018) further argued for historical globalization as being based not merely on the desire to expand international trade, but on additional 
Table $1.1 \quad$ Percentage of merchandise trade (exports and imports) of GDP at 1995 prices in selected countries, 1913-95

\begin{tabular}{lll}
\hline Country & 1913 & 1995 \\
\hline France & 35.4 & 36.6 \\
Germany & 35.1 & 38.7 \\
Japan & 31.4 & 14.1 \\
Netherlands & 103.6 & 83.4 \\
UK & 44.7 & $42.6(1994)$ \\
US & 11.2 & 19.0 \\
\hline
\end{tabular}

Source: Hirst and Thompson 1998, 23.

motivations led by religious expansion, geographical exploration and political domination.

Contemporary globalization has its more direct roots in the colonization efforts, which followed the geographical exploration of the globe, as of the fifteenth century, led at the time by Spain and Portugal, and followed later by additional European countries, notably the United Kingdom (UK), France and the Netherlands (Gopinath 2018). These geographical explorations involved also a religious missionary zeal, and they were followed by imports from the newly discovered territories, which turned into colonies, to the dominating colonial power, thus enhancing the prosperity of the latter, as prescribed by the leading, at the time, Mercantile economic theory. The economic governing of the colonies went hand in hand with their political domination. In some ways, Europe was dependent on imports from its colonies. For instance, in the eighteenth and nineteenth centuries, Haiti supplied some 40 percent of the sugar consumption by the UK and France (Eyal 2018, 69).

Growing international trade among countries joined the growing trade between European colonial powers and their colonies, peaking in the Belle Époque era, between the end of the Prussia-France War in 1871 and the year before the beginning of the First World War in 1914. The Belle Époque era was coupled also with immense migration waves, mainly from Europe to North America, side by side with the introduction of leading inventions and innovation, such as electricity, cinema, the telephone and automobiles (Eyal 2018). Thus, during this era international trade grew at an average annual rate of 3.5 percent (Wright 2000, 109). Furthermore, as Table 1.1 exemplifies, the share of international trade out of the gross domestic product (GDP) of numerous nations worldwide reached high rates, which have been repeated only in contemporary globalization, as of the mid-1990s (Hirst and Thompson 1998).

Numerous leading factors, events and processes, leading eventually to contemporary globalization, had emerged already as of the 1940s. These 
range along political, economic and technological dimensions, and they have powered contemporary globalization, which has emerged as of the 1970s, and which matured in the 1990s (Table 1.2). Politically, the fall of the Soviet Union and the related end of the Cold War between the United States (US) and the Soviet Union, both being coupled by the opening of China for foreign impacts, investments and trade, have permitted free trade and movements at a global scale. Technologically, globalization has been powered by the evolution of contemporary telecommunications, which has facilitated instant and cheap communications of all forms, notably as of the commercial introduction of the Internet in the mid-1990s.

Looking at contemporary globalization through the lenses of previous waves of worldwide international relations identifies a thin borderline between globalization, on the one hand, and international trade, on the other, in past waves of globalization. Thus, even the Belle Époque era included, at the time, in addition to expanded international trade, only one-way international human movements of migration, whereas contemporary globalization constitutes a deeper and much more diversified reality. International trade takes place not only among governments, with its performance carried out by big companies, some of which are multinational in character, but by small companies as well.

The global movements of individuals have also expanded. Thus, global movements by individuals now involve mainly two-way short trips for business and pleasure, carried out through big passenger airplanes, which did not exist before. International tourism is a striking physical mobility attesting to contemporary globalization as involving the numerous individuals, performing personal international trade of products and services, using their smartphones and computers, and being constantly exposed to global information of all kinds: news, knowledge and entertainment (see also Section 11.1). Thus, contemporary globalization does not take place only through governmental activities but also by individuals located elsewhere worldwide. The globe can be, and frequently is, conceived by individuals as a single action space for their numerous daily activities pursued over the Internet, TV and other media.

\section{$1.3 \quad$ SPATIAL MOBILITY}

The notion of spatial mobility has been elaborated elsewhere (Kellerman 2012, 2018), so it will only be shortly outlined in this section. Spatial mobility constitutes the human natural ability to shift or move one's body across space, as well as the ability of humans to move their limbs in situ. Spatial mobility further constitutes the ability of humans to move themselves across space by using either ancient or contemporary mobility technologies. In addition, spatial mobility includes the human ability to move objects across physical space making use of shipping technologies and vehicles. Spatial mobility also 


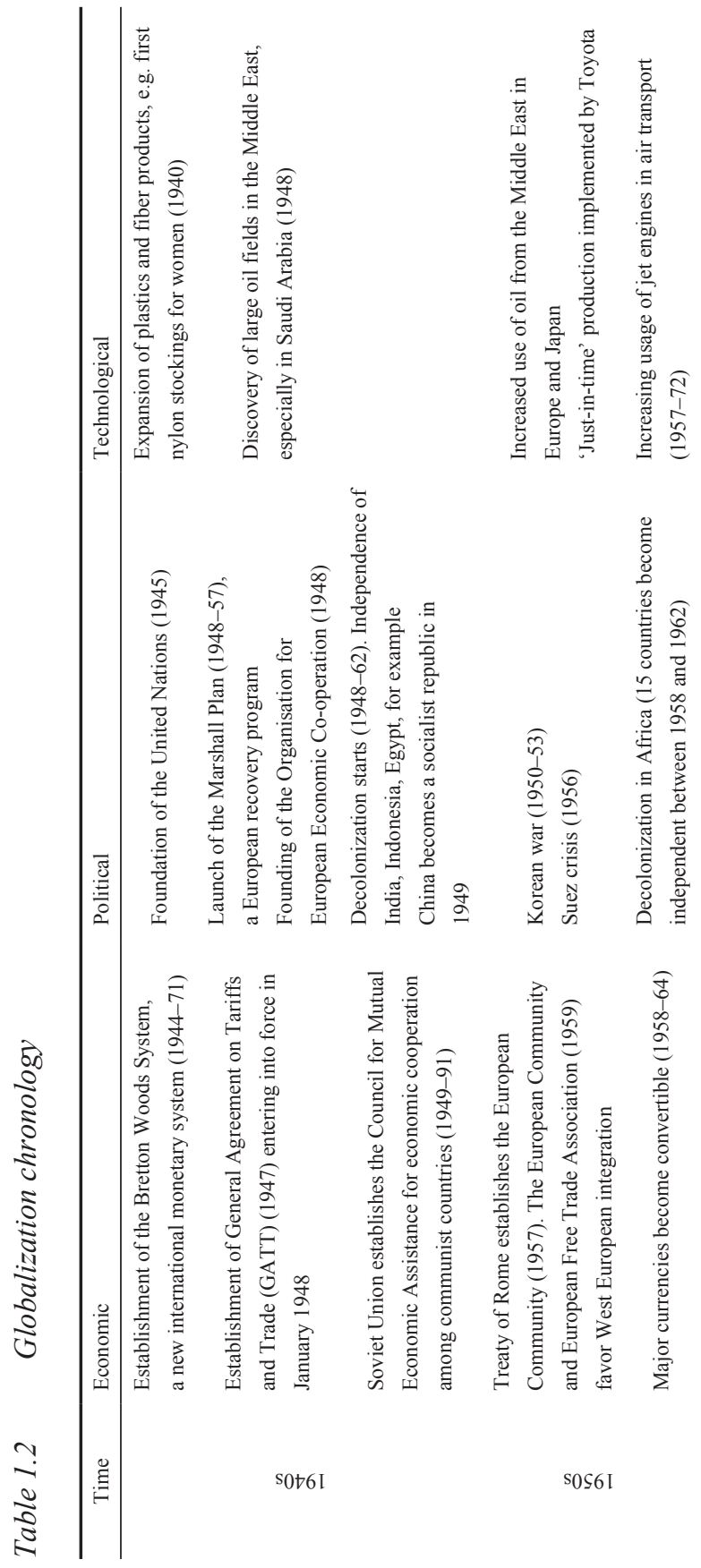



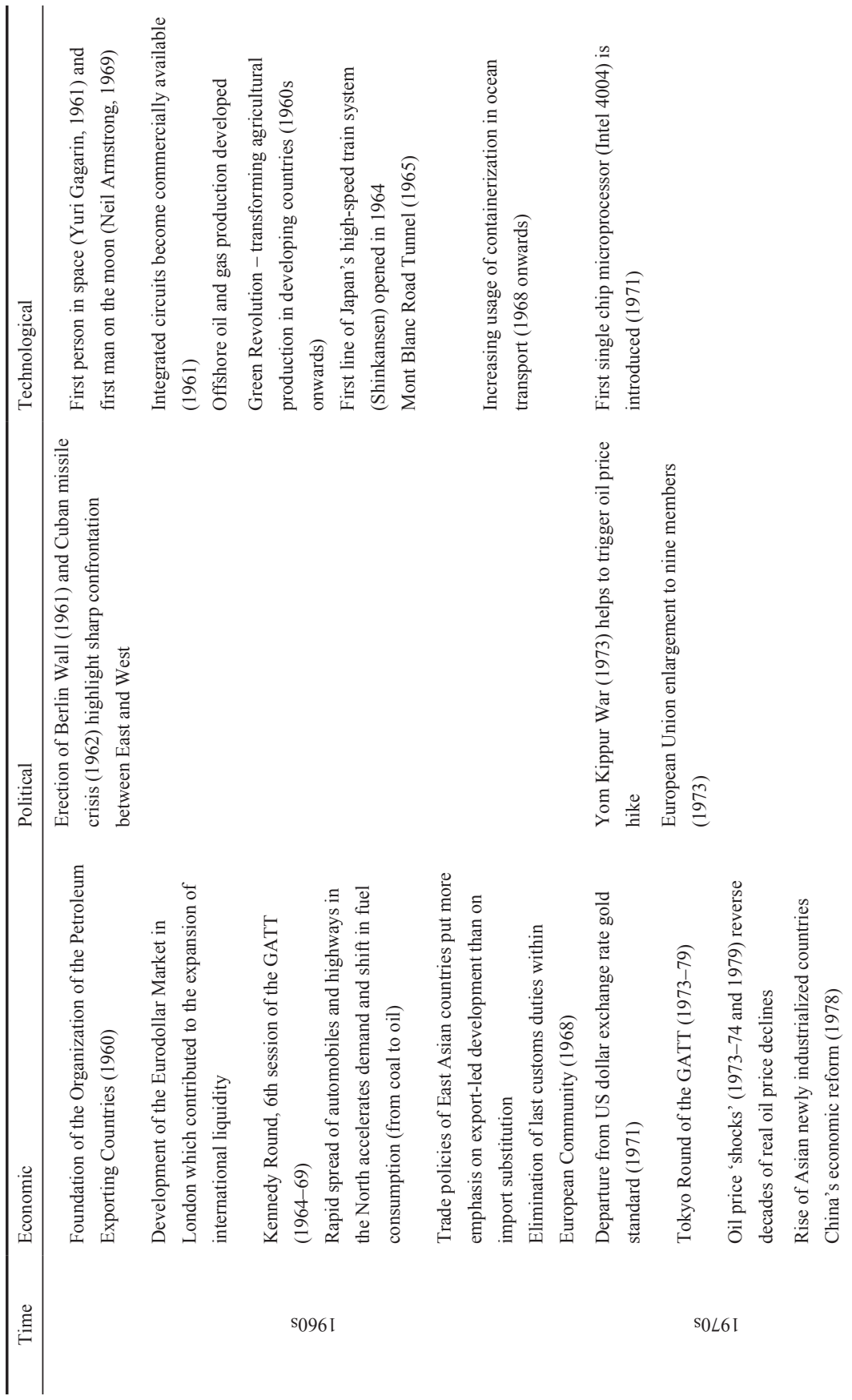


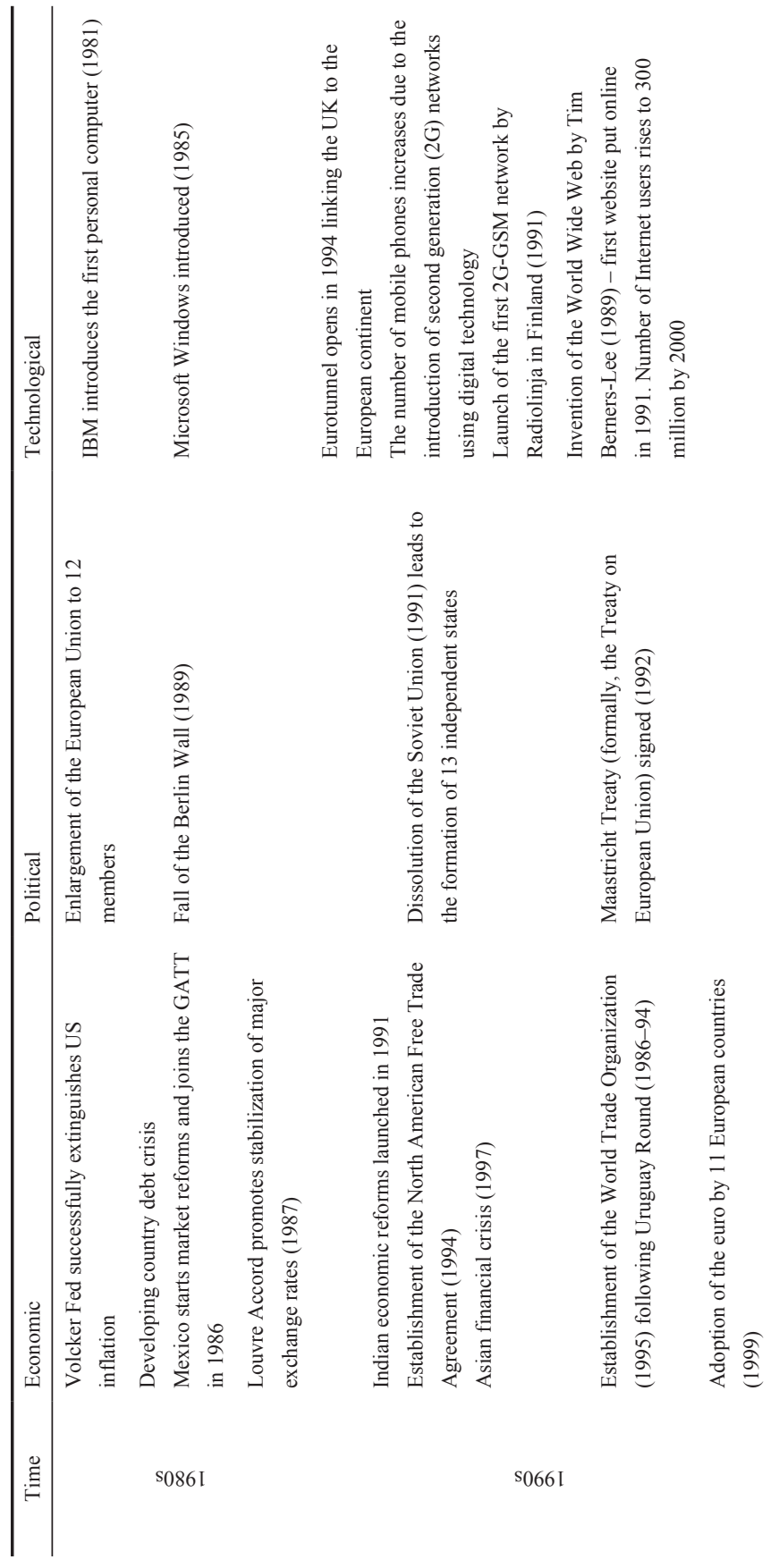




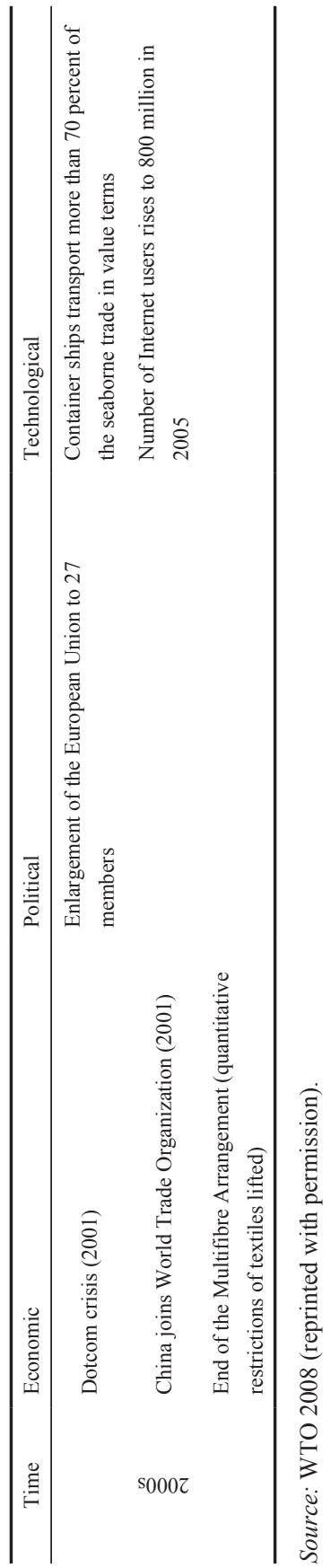


includes the human ability to move information of all types, through its virtual sending, retrieval or arrival.

Specific spatial movements of one's body, one's material objects or one's information, using any transport vehicle or any communications device, involve a generally similar movement process. Thus, one's body, object or information is led by proper vehicles or devices, as chosen by their users, from an origin (fixed or mobile), through some routes (e.g. roads, airlines, public transportation lines, telephone lines) to a chosen destination. Each movement is further being managed en route through any traffic control mechanisms (traffic lights, airport or harbor control centers, routers, exchanges, etc.), until the reaching of the predefined destination (fixed or mobile) (see also Kellerman 2011).

Beyond and beside these rather basic elements of any particular spatial movement, spatial mobility in general has been variously interpreted as displacement, as a meaningful condition, as an activity and as an ability (Kellerman 2018). As far as global mobilities are concerned, the view of mobility as displacement is in focus here. The physical shifting of humans or things over space always involves displacement, whether it is minor and repetitive as, for instance, is the case for daily commuting, or whether such shifting is major and one-way, such as in migration. Displacement constitutes the essence of spatial mobility, 'displacement of something across, over and through space' (Adey 2010, 13; see also Cresswell 2006, 1-2; Morse 1998, 112). It is possible to view mobility as displacement for three sorts of movables: people, objects and information/knowledge (Urry 2007, 7-8, 47; Kaufmann 2002), and these three movables may be differentiated by their mobility flexibility, using a state of matter metaphor (Kellerman 1993, 160). Moving information is as flexible as gas, in its easily changing modes, shapes and volume, as well as in its very transmission being instant. People's corporeal mobility may be viewed as being similar to liquid, exhibited through people's ability to change travel modes, as well as through their ability to be partially self-motored. Moving objects constitutes the very moving of solids, which by its very nature is slower and always requiring handling. All of these three movables are human in some way, since objects and information are sent by people and for people, and sometimes such mobilities, notably of information, may even replace human corporeal mobility.

Spatial mobility as displacement accentuates a condition. However, given the extensive and complex dimensions of spatial mobility, its study is not just interested merely in displacement and in shifts per se, but also in their contexts and significances. As such, the study of spatial mobility stretches beyond transportation geography (Shaw and Hesse 2010; Bissell et al. 2011). Any shift or mobility 'is given or inscribed with meaning. Furthermore, the way it is given meaning is dependent upon the context in which it occurs and who 
decides upon the significance it is given' (Adey 2010, 36). Spatial mobility, as displacement, has been viewed as a positive societal trend and force and as an integral part of the second modernity involving wide social implications (see e.g. Urry 2000, 2007). Spatial mobilities of individuals may further be differentiated along major demographic parameters, for instance gender (see e.g. Blumen and Kellerman 1990), age (see e.g. Burnett and Lucas 2010) and obviously income.

Another relevant basic definition for spatial mobility, this time from the perspective of transportation geography, viewed mobility as an ability: 'Mobility refers to the ability to move between different activity sites' (Hanson 1995, 4). Similarly, movement was described as 'the idea of an act of displacement that allows objects, people, ideas - things - to get between locations' (Cresswell 2001, 14), whereas others provided a rather social and more restricted definition for mobility, referring to an actor's competence to realize certain projects and plans while being 'on the move' (Bonss and Kesselring 2004, 5).

The recent telecommunications/information revolution has emphasized the virtual dimension of the term spatial mobility, referring to the human ability to move a rather abstract entity, information, electronically over space, and thus carrying out virtual spatial mobility. The growing significance of virtual mobility, and its integration with physical spatial mobility, which we will note later, mainly in Chapters 8-9, calls for some initial attention to it here. Electronically transmitted information may constitute a virtual extension of the self, even internationally, through a phone call, through an e-mail or through other electronically sent messages. Alternatively, virtual mobility may constitute public pieces of information, available through websites, so that as such they are not being transmitted as one-to-one messages or as one-to-many messages, oriented from one user to some specifically denoted receivers. Such website information constitutes, therefore, rather on-demand retrieved information.

The physical mobility of people has increasingly involved, as of the 1970s, virtual transfers of information, as well. For instance, information transmitted for travel booking and coordination, or for traffic control. Communications have become a crucial key for the management of people's physical mobility.

From yet another angle of joint physical and virtual mobilities, it has become possible for individuals to move corporeally while simultaneously communicating virtually through smartphones. Moreover, even the mobilities of people and objects are interrelated: 'There are objects that enable people to travel across distance; there are objects that enable people to travel forming complex hybrids... there are objects and people that move together' (Urry 2007, 50). The mass moving of objects has become increasingly organized and controllable through logistics and modal transportation. Individuals, on the other hand, tend, in many cases, to prefer individual mobility for their daily 
commuting, making use of personal mobility vehicles, i.e. cars, motorcycles and bicycles.

Contemporary globalization is characterized, from the perspective of spatial mobility, in the ease of movement made possible for people, objects and information across international borders, so that the differences between domestic and international mobilities have decreased enormously. Thus, information moves completely freely across international borders unless some censorship is imposed (see Warf 2013), and people and objects in most cases require, these days, minimal permits in order to move internationally. This relationship between domestic and international mobilities may sometimes also go the other way around. Thus, security requirements, originally imposed only for international passengers, are now imposed for domestic ones, as well (Kellerman 2008).

\subsection{GLOBAL MOBILITIES}

Globalization consists, in its very essence as process and pattern, of a series of global mobilities, jointly constituting the mobile globe. These global mobilities include, as we noted already, commodities, people, capital, information and technology. Numerous dimensions connect globalization and this rather varied list of mobilities:

1. Mobile agents and entities: As mentioned already, globalization involves numerous mobile agents and entities, including people, commodities, capital, information and technology (Urry 2007).

2. Continuous process: Globalization was argued to constitute 'an evolving phenomenon and [it] is all around us. It is a process and not a state of affairs' (Gopinath 2018, 6). The nature of globalization as a continuous process has been materialized through global mobilities, as experienced by individuals, organizations and governments alike.

3. Systems: Mobilities in general and global ones in particular are based on systems which are comprised of infrastructures, and which facilitate movements. These systems or infrastructures include ports and airports, airplanes and boats, pipelines, telephone lines and satellites, side by side with systems that permit the pursuance of mobility, such as ticketing machines (Urry 2007, see also Shamir 2005).

4. Circulation: Global mobilities, as well as domestic ones, include a variety of circular movements, such as reciprocal seasonal-produce shipments, regular flights by airlines and scheduled capital and information transmissions. Along with these circular movements, others are non-circular, such as one-way technology, as well as some commodity shipments (Urry 2007). 
5. Two-way feeding: Globalization and mobility have mutually fed each other, so that the development of personal communications technologies and media, and the opening of obstacles for smooth international travel, have brought about immense virtual and physical mobilities by individuals. These latter growing movements have served as catalysts for the emergence of additional technological developments and organizational changes, geared for increased and more efficient global movements.

6. Hybridity between globalization and mobility: Some of the contemporary day-to-day nature of the relationships between globalization and mobility constitute a hybridity, manifested through the daily lives of individuals. This hybridity relates mainly to the daily virtual movements of individuals, a significant part of which is carried out within a domestic physical framework, but is global by its routing and destinations. Such are global Internet surfing and online activities, which may be performed by individuals while riding a local train, international telephone calls taking place while driving and listening to Internet radio stations, again while driving. There is also international shopping online, as well as merchandise price comparison over the Internet while being located in a real space store. The Internet and telephone systems are by their very contemporary nature global communications technologies, so that sometimes local physical activities may be tied with international ones (Kellerman 2019).

7. Complex operations: The facilitation and operation of global mobilities are complex, and they have become possible through the development of technologies. These technologies include IT, mainly computers for the management and control of global movements, and telecommunications for global interactions by people and machines. These technologies further include transportation, for instance big airplanes and boats, structured for long-distance travel and shipping.

The emergence of the global dimension in the economic, social and spatial spheres has involved some political change as well, a transition that simultaneously nourished the previously mentioned changes. As Deleuze and Guattari (1986) and Urry (2000) showed, the traditional nation-state, which has been based mainly upon territory and its symbolism, has taken the role of a controlling and regulating entity, focusing mainly on the management of mobilities. This has been the case regarding domestic mobilities, whether in the form of car and drivers' licensing, or in the form of regulating the growth and privatizing of communications services. This has further become the case for global mobilities, where the nation-state has become a rather sophisticated gatekeeper, licensing the activities of companies and people and, thus, maintaining some interest in economic and organizational goings-on beyond its territorial boundaries. 


\subsection{OBJECTIONS TO GLOBALIZATION}

Contemporary globalization has been met with extensive objections, channeled frequently through alter-globalization movements (Miller 2018). The objections to the emerging course of globalization have been conceptual as well as practical-political, leading to some recent slowing down and withdrawals from its continued fostering, at least at the governmental and political-sectoral levels. Thus, globalization was viewed as involving highly contradictory normative and cultural pressures, between democracy and capitalism, between south and north, as well as between the haves and the have-nots (Hardt and Negri 2000; Shamir 2005). At the non-governmental organization level, the World Economic Forum served as a leading pro-globalization global voice, whereas the World Social Forum (Gopinath 2018) advanced anti-globalization views. Globalization was favored by arguing for its provision of expanding cultural, social and economic opportunities for individuals, while it was opposed for its supposed cutting of national political, economic and cultural sovereignties.

In the 2010s, the objections to globalization achieved national political victories worldwide, led by the British Brexit (British Exit) from the European Union, by the President Trump-led US international trade sanctions, notably against China, and by rightist European governments opposing continued Muslim immigration. The revolt against globalization seems to present societal yearning for stability in a world that seems to move faster and faster into misunderstood directions (Eyal 2018). Such revolts at the national level are widely spread, but there are, of course, countries which favor continued globalization, as long as it develops along their preferred style, e.g. China (see Section 12.2).

Along with growing objections to globalization at the national and governmental levels, the immense adoption of smartphones and the wide exposure to the Internet and its adoption by individuals have brought about widely expanded personal imports of products and services from anywhere worldwide, through online shopping, which we will discuss in Chapters 3 and 8 (Kellerman 2019). The ease and convenience of smartphones, the Internet and personal computers, and their provision of wider merchandise selections at lower prices, seem to make the possibility of personal globalization turning back next to impossible. Another expression of personal globalization is expanded tourism, aided by the introduction of low-cost airlines and airports. Growing tourism has brought about objections by residents of highly visited cities (see e.g. Vargas-Sánchez et al. 2014). However, growing local objections to incoming tourism may not reduce the globally expanded tourism, but rather channel some of it to new destinations. 
Globalization may further be viewed differentially by business. On the one hand, there are multinational corporations, which by their very nature constitute an expression of global business construction, and on the other hand, there are domestic companies, which may frequently feel threatened by growing international and multinational competitions (see e.g. Osland 2003).

Globalization involves, therefore, several major sectors in every country: governments and political parties along with individuals and business communities. Each of these sectors may have their own interests and expectations from globalization, expressed through the fostering or through objections to various strata of contemporary globalization.

\subsection{CONCLUSION}

This book aims at the joint and comparative examination of the voluntary global movements of commodities and people, capital, information and technology. It thus excludes forced migrations of refugees. The book will present for each movement its mobility infrastructure and vehicles, along with its patterns and processes.

The very nature of globalization has been assessed from three angles: First, globalization might be conceived as a kind of a system, the network society, consisting of spaces, flow routes and movement vehicles, all of which facilitate global mobilities. Second, globalization also constitutes the wide variety of seamless global mobilities themselves, including people, commodities, technologies and cultures. Third, and from a radical perspective, globalization has been assessed to amount to transnational capitalism, expressed through the global movements of capital.

Definitions for globalization focus on relevant processes and patterns, and they jointly reflect the societal facets of globalization, whether it be a system, a collection of movements or a capitalist venture. These definitions present, therefore, numerous meanings and significances of globalization for people, as well as for countries, both of whom simultaneously activate globalization and are activated by it. Definitions for globalization are even more varied than the three perspectives suggested for the nature of globalization, and they refer to processes and outcomes, integration, social relations, the existential environment, experience, social processes, barrier removal and human activity.

Globalization already existed in ancient times, but it has its contemporary roots beginning with the geographical global explorations, which were followed by colonization efforts as of the fifteenth century by numerous European nations. International trade, based on colonization, culminated in the Belle Époque era, between the end of the Prussia-France War in 1871 and the year before the beginning of the First World War in 1914. 
Contemporary globalization, which has emerged as of the 1970s, and which matured in the 1990s, has been powered by several leading factors. Politically, the fall of the Soviet Union and the related end of the Cold War between the US and the Soviet Union, coupled with the opening of China for foreign imports, investment and trade, have permitted free trade and movement at a global scale. Technologically, globalization has been powered by the evolution of contemporary telecommunications, which has facilitated instant and cheap communications of all forms, notably as of the emergence of the Internet in the mid-1990s.

Spatial mobility constitutes the natural human ability to shift or move one's body across space, as well as the ability of humans to move their limbs in situ. Spatial mobility further constitutes the ability of humans to move themselves across space by using either ancient or contemporary mobility technologies. In addition, spatial mobility also includes the human ability to move objects across physical space, making use of shipping technologies and vehicles. Spatial mobility further includes people's ability to move information of all types, through its virtual sending, retrieval or arrival.

Globalization consists, in its very essence as process and pattern, in a series of global mobilities, jointly constituting the mobile globe. These global mobilities include commodities, people, capital, information and technology. Numerous dimensions connect globalization and this rather varied list of mobilities: mobile agents and entities, continuous processes, systems, circulation, two-way feeding, hybridity between globalization and mobility, and its rather complex operations.

Contemporary globalization has been met with extensive objections, conceptual as well as practical-political, leading to some recent slowing down and withdrawals from its continued fostering, at least at the governmental and political-sectoral levels. Thus, globalization was viewed as involving highly contradictory normative and cultural pressures, between democracy and capitalism, between south and north, as well as between the haves and the have-nots.

Globalization involves several major sectors in every country: governments and political parties, side by side with individuals and the business communities. Each of these sectors may have their own interests and expectations from globalization, expressed through the fostering or, alternatively, through objections to various strata of contemporary globalization. 